\title{
Community refinement of glaucoma referrals
}

DB Henson ${ }^{1}$, AF Spencer ${ }^{1}$, R Harper ${ }^{1}$ and

EJ Cadman²

\begin{abstract}
Aim To describe a Manchester-based glaucoma referral refinement scheme designed to reduce the number of false-positive referrals to the hospital eye service. To report on the first years results of this scheme and its financial costs to the NHS.

Methods Patients with suspected glaucoma, instead of being referred to their GP and then on to the hospital eye service, were referred to a group of specially trained community optometrists working to an agreed set of referral criteria. Those patients who did not meet the referral criteria were returned to the referring optometrist, while those who met the referral criteria were referred directly to Manchester Royal Eye Hospital. The patient's GP was informed in all cases.

Results The number of suspect glaucoma cases referred to the Manchester Royal Eye Hospital was reduced by $40 \%$. This figure is close to the percentage of false-positive referrals measured at Manchester Royal Eye Hospital prior to the onset of this study. The information accompanying referral has been improved and the scheme produces a small financial cost saving to the NHS of approximately $£ 17$ per patient.

Conclusion Community refinement of suspect glaucoma offers some important benefits over the current referral pathway. Eye (2003) 17, 21-26. doi: 10.1038/sj.eye.6700261
\end{abstract}

Keywords: glaucoma; optometry; referral criteria

\section{Introduction}

In the UK, the vast majority of suspect glaucoma patients seen within the Hospital Eye Service (HES) are referred, via the patient's general practitioner (GP), by community optometrist. ${ }^{1}$

A significant proportion of these referrals are subsequently found to be false positives $(20-65 \%)$, that is, there is little if any evidence of glaucoma. ${ }^{1-7}$ These false-positive referrals place unnecessary demands upon an already overstretched resource and contribute to the long waiting times between GP referral and outpatient department (OPD) appointments. The false referrals also incur considerable financial costs, both for the NHS itself and to the patient (travel, lost time at work). In addition, there may be psychological costs, with unnecessary anxiety in the referred patient, who is informed that they may have glaucoma and yet often have to wait 2-3 months before getting an OPD appointment.

The high proportion of false positives is, in part, a reflection of the low prevalence of undetected glaucoma within the community ( $<1 \%$ in patients over 40 years of age). Even with a high specificity, the positive predictive power of a referral is going to be low; for example, if the residual prevalence is $1 \%$, specificity is $99 \%$ and optometrists detect all cases of glaucoma, $50 \%$ of the referrals will be false positives. However, it is clear from the data submitted with referrals that in some cases little effort has been made by the referring optometrist to ensure that the referral was justified, for example, cases in which the only information submitted is a single measurement of the IOP of $<26 \mathrm{mmHg}$.

Despite the problems created by these false referrals, there have been very few attempts to find a solution. Vernon and Gosh ${ }^{8}$ established that the provision of specific referral guidelines, circulated to all optometrists working within the catchment area, had little effect on the proportion of false referrals.

In this paper, we report on an alternative solution that has been trialed in Manchester for the past year. Patients with suspected glaucoma, instead of being referred to their GP and then on to the OPD, are referred to a group of accredited optometrists working within their own practices. These optometrists work to an agreed set of referral criteria and, depending upon whether or not the patient meets these criteria, either refer the patient directly to the HES or return them to the referring optometrist. They
${ }^{1}$ Manchester University and Manchester Royal Eye Hospital

Manchester, UK

${ }^{2}$ Knutsford,

Cheshire, UK

Correspondence:

Dr David B Henson

Academic Department of Ophthalmology

Manchester Royal Eye

Hospital

Oxford Road

Manchester M13 9WH, UK Tel: +441612765507

Fax: + 441612736354

E-mail: david.henson

@ man.ac.uk

Received: 26 November 2001

Revised: 4 April 2002 


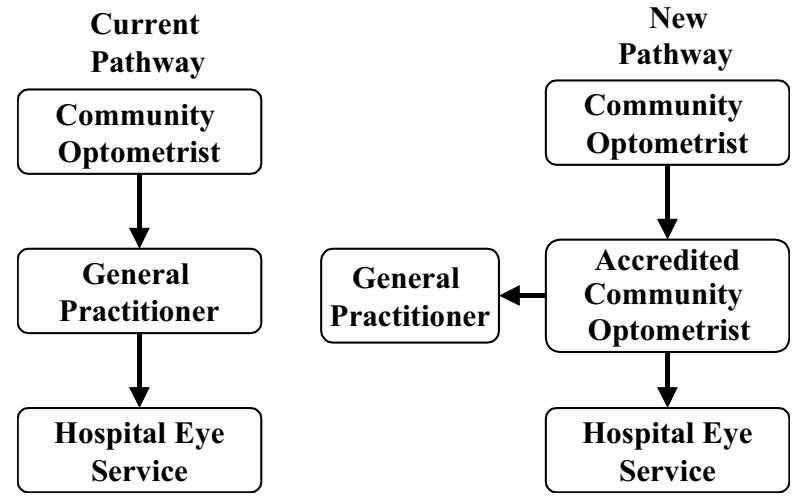

Figure 1 The current and new referral pathways for suspect glaucoma cases.

also report their findings to the patient's GP (see Figure 1). This paper describes this scheme and reports on its first year outcomes along with estimates of financial costs / savings over a 3-year period.

\section{Methods}

\section{Selection of optometrists}

Following discussions with both the Manchester Local Optical Committee and the Manchester Health Authority (MHA), all optometrists submitting sight test claims to the MHA were invited to attend a meeting at which the proposed scheme was presented. At the end of the meeting, optometrists were invited to apply for accreditation training. Criteria for accreditation included, working within the MHA's boundaries, registration with the General Optical Council for 3 or more years, no more than one optometrist from any single practice address, and availability to attend the whole of the training programme. A total of 18 optometrists met these criteria and volunteered to undergo training.

\section{Training scheme for accreditation}

Training comprised of three evenings of lectures covering glaucoma epidemiology, optic disc assessment, tonometry, and visual fields (these lectures were made available to all optometrists working within the Manchester area). The 18 optometrists undergoing accreditation also had two (4h) practical sessions devoted almost entirely to disc assessment using binocular indirect ophthalmoscopy with a noncontact fundus lens and slit-lamp biomicroscope. The optometrists examined up to 20 patients per session and filled in task sheets for each case. These task sheets requested specific information about the optic nerve head, similar to that required in the referral forms (see Figure 2). At the end of the session, the optometrists had a tutorial to discuss their findings at which high-quality digital optic nerve head images of the patients attending the practical sessions were available. A glaucoma specialist assessed the performance of the optometrists from their worksheets. Of the 18 optometrists who took the training course, 15 went on to be accredited. One of the optometrists who did not reach accreditation was unable to complete the training course and two had difficulties in assessing the optic nerve head and agreed to drop out of the scheme with a view to gaining further training the next time the course was run.

In addition, all accredited optometrists subsequently attended the OPD for one half day every 6 months in order to update their skills and discuss cases with a consultant/fellow.

\section{Equipment used and referral criteria}

Accredited optometrists use contact applanation tonometry (Perkins Hand Held or Goldmann slit lamp mounted), indirect ophthalmoscopy (78D recommended) and perform a suprathreshold visual field test with one of the following instruments (Dicon 400, Henson Bowl Perimeter, Humphrey Visual Field Analyzer (600 or 700 series)) on all patients referred through the scheme. A copy of a completed referral form is given in Figure 2.

The criteria used by these optometrists to decide whether or not patients should be referred on to the HES are as follows.

\section{Single referral criteria}

(1) IOP $>26 \mathrm{mmHg}$ confirmed at a second visit. If IOP $>35 \mathrm{mmHg}$, then no confirmatory measurement is necessary.

(2) Unequivocal pathological cupping at the optic nerve head. Abnormal neuroretinal rim configuration. Large cup, taking into account the overall size of the disc. Notched neuroretinal rim. The existence of a disc haemorrhage merits closer inspection for early nerve fibre loss. $\geq 0.2$ asymmetry of cup-to-disc ratio.

(3) Visual field loss, consistent with a diagnosis of glaucoma, confirmed at a second visit. If explained by other disc or retinal pathology to be referred as such and not through scheme.

\section{Combined referral criteria}

(1) $\mathrm{IOP} \geq 22 \mathrm{mmHg}$ plus an optic disc appearance suspicious of glaucoma or optic disc asymmetry.

(2) Abnormal optic disc and visual fields (IOP not raised) (no need for confirmatory measures).

\section{Additional referral criteria}

(1) Optic disc change, for example, increase in cup size, change in the rim appearance, or the occurrence of a new haemorrhage. 


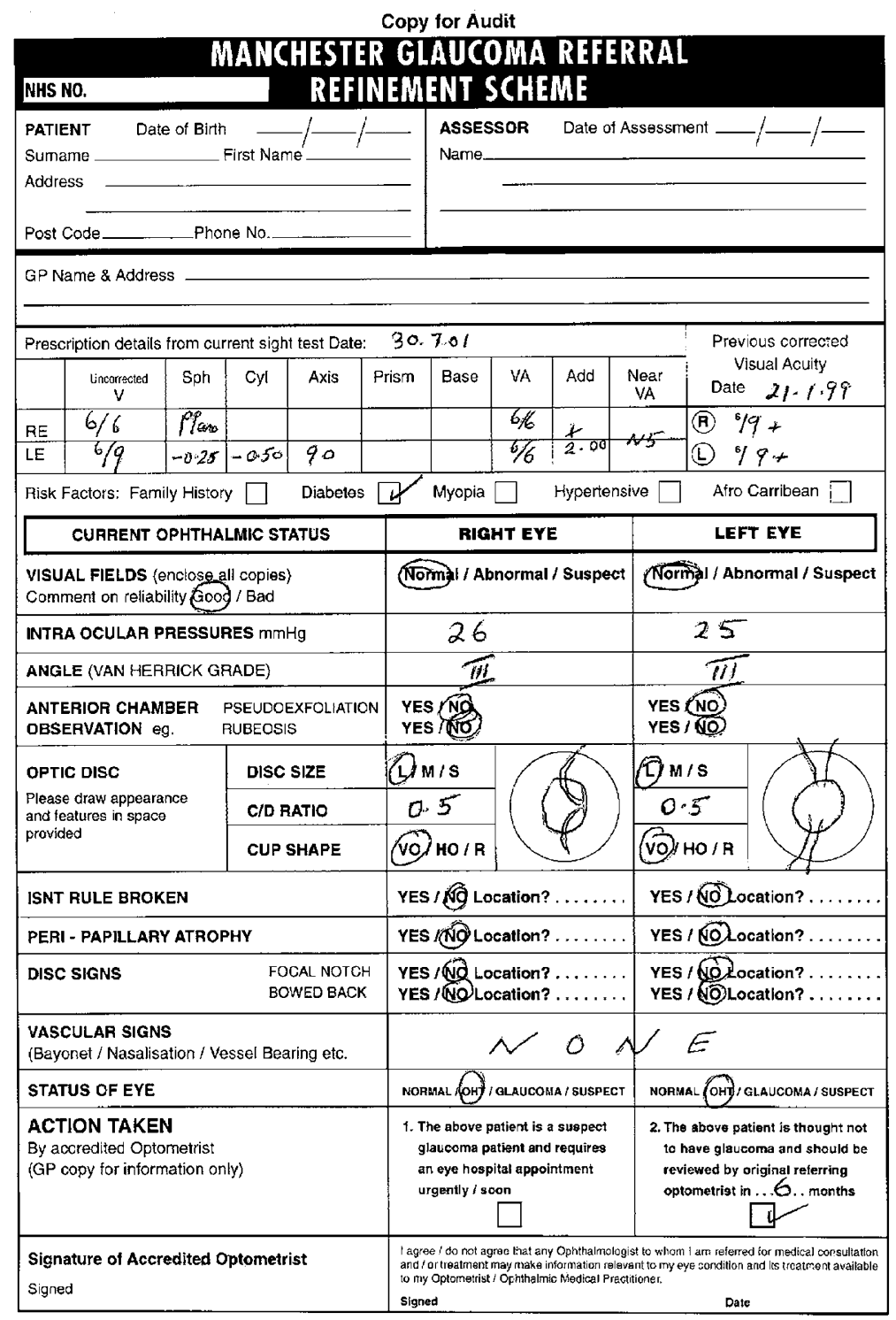

Figure 2 Example of a completed referral form that accompanies each patient along with visual field charts.

(2) Anterior segment signs of secondary glaucoma (eg pseudoexfoliation) with IOPs $>22 \mathrm{mmHg}$ on two occasions.

(3) Suspect narrow-angle glaucoma (subacute attacks or closeable angle and IOP $>22 \mathrm{mmHg}$ ).

Patients of the accredited optometrists who meet the referral criteria are referred directly to the HES.

\section{Audit trail}

A copy of the accredited optometrist's findings is sent to the referring optometrist, MHA, and to the GP. The MHA version initiates payment (£35) and is forwarded to $\mathrm{MREH}$ for audit purposes. If the patient is referred to the
HES, then an additional copy is sent along with visual field data.

All optometrists and GPs working within the MHA were informed about the new referral route which was only for patients whose GPs worked within the boundaries of MHA. Optometrists in neighbouring health authorities were also informed, as it is possible for them to have patients whose GPs work within the MHA.

To help establish the financial costs/savings of the scheme, it was necessary to obtain an estimate of the number of visits that patients referred under the old scheme made prior to being discharged as a false referral. To obtain this information, a review was undertaken of new referrals to MREH made in 1997. Using the hospitals patient appointment system (PAS) database, all 
new suspect glaucoma referrals from optometrists made in every fourth week throughout the year were reviewed. Those cases that were subsequently discharged as false positives were then analysed to see how many OPD appointments they made prior to discharge.

\section{Results}

The number of patients assessed in the scheme so far is given in Figure 3. During the first few months, there was a gradual increase in number as the new referral route took over from the old one. From December 2000, patients referred via the old pathway were returned to their GP for re-routing to an accredited optometrist, with a reminder being sent to the referring optometrist.

In total, 194 patients have been passed through the scheme, of which 112 were referred to the MREH $(58 \%)$. The average number of patients/month for February through to August is 23. The falloff after August is due to delays in data going through the audit process.

A total of 93 (equivalent to 372/annum) suspect glaucoma referrals were found from the review of referrals in 1997. Of these referrals, 34 were discharged (37\%) and on average each discharged patient made 2.33 visits to the OPD.

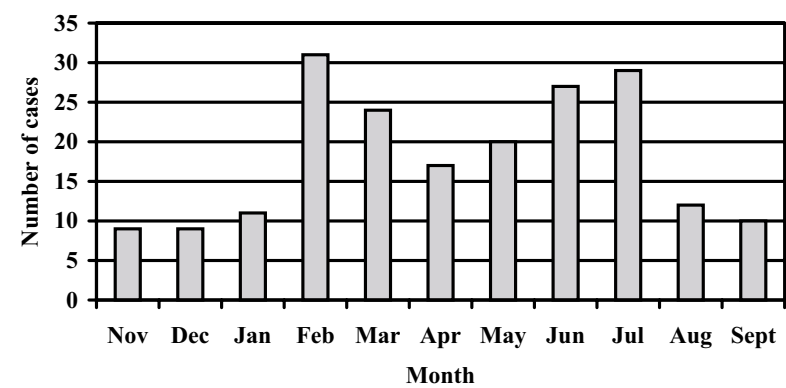

Figure 3 Number of cases passing through the scheme.

\section{Financial analysis}

Table 1 provides an estimate of the costs/savings over a period of 3 years. In making these calculations, a number of assumptions have been made:

1. The training programme will have to be repeated every 3 years to increase the pool of accredited optometrists and to refresh the skills of those already accredited. Within the first year, three optometrists moved out of the area leaving a residual pool of 12 accredited optometrists.

2. The scheme will continue to see 23 patients/month and $42 \%$ of these will not be referred to the HES.

The cost saving works out to be approximately $£ 17 /$ patient passing through the scheme.

\section{Discussion}

The community refinement of glaucoma referrals scheme set up in Manchester has reduced the number of glaucoma referrals to MREH by approximately $40 \%$. There are several factors that have contributed to this reduction. The examination by the accredited optometrists acts as a confirmatory test of the original optometrist's findings. This will reduce the false-positive rate. The use of all three diagnostic tests (IOP, visual fields, and disc evaluation) will also help to reduce the number of referrals as will the routine use of contact applanation tonometry and binocular optic nerve head assessment which are perceived to be more accurate than noncontact tonometry and direct ophthalmoscopy. ${ }^{9}$ Another factor contributing to the reduced number of referrals is the utilisation of clear referral criteria and the provision of a training programme for the accredited optometrists that incorporated practical sessions on optic nerve head evaluation.

There are several important benefits accruing from the Manchester scheme. The most obvious of these is the reduction in the number of referrals to MREH. This redirection will release appointment slots and contribute

Table 1 Costs/savings of the scheme over a 3-year period

\begin{tabular}{|c|c|c|c|}
\hline & Savings (£) & Costs $(£)$ & Notes \\
\hline Training of optometrists & & 8007 & Total cost \\
\hline Fees to optometrists & & 27300 & $\begin{array}{l}780 \text { at } £ 35 / \text { visit. } 21 \text { cases in first } 3 \text { months and then } \\
23 / \text { month for } 33 \text { months }\end{array}$ \\
\hline \multicolumn{4}{|l|}{ Administration } \\
\hline Handling of optometrists claims & & & Minimal \\
\hline Audit & & 5000 & Estimate \\
\hline MREH nonreferred cases & 42033 & & 328 patients not referred, 2.33 visits/patients at $£ 55 /$ visit \\
\hline GP visits & 11700 & & 780 at $£ 15 /$ visit \\
\hline Total & 53733 & 40307 & \\
\hline
\end{tabular}


to a reduction in OPD waiting times. Patients will not have to travel so far for their appointment, the accredited optometrists being fairly evenly distributed throughout the authority's boundaries. There is more flexibility in appointment times, and patients will rarely have to wait more than a few moments before being seen. Patients will have their visual fields, IOPs, and optic nerve heads evaluated in a single session with the accredited optometrist rather than having to have different appointments for their visual field examination and to 'see the doctor' (these appointments may be on separate days).

Another benefit of the Manchester scheme is its clear reporting pathway with clear lines of responsibility. The accredited optometrists in this scheme are responsible for the decisions they make and are covered for any liability by their professional insurance. The provision of audit data to the MREH has made it possible for each of the accredited optometrists to be evaluated against our own measurements. This process is currently taking place and will be used to give feedback to accredited optometrists as part of their ongoing training.

This paper has not reported on the false-positive rate of the accredited optometrists, as accurate statistics will not be available until patients have made several visits to the MREH. Currently, some $36 \%$ of referrals are being monitored by the hospital and these could, in the future, be either discharged (a false positive) or treated (a true positive), a future paper will address these findings.

In the calculation of costs/savings, it was assumed that the numbers passing through the scheme would continue at the current steady rate of approximately $23 /$ month, with $42 \%$ of the cases not being referred to the HES. There are two factors that could change this state of affairs. The nonaccredited optometrists after seeing a number of returned referrals could begin to adopt referral criteria that more closely match those of the scheme. This factor would reduce the number of false referrals and would increase the cost effectiveness of the scheme by reducing the number of referral refinements. The original objectives, of reducing the number of false referrals would be retained.

Alternatively, optometrists might, because of the scheme, feel that there was no need for them to do so many tests prior to referral as these are only going to be repeated by the accredited optometrist. As there is a good relationship between the accuracy of referrals and the number of tests performed by the optometrists, ${ }^{10}$ this change might arguably increase the number of false referrals and increase the total costs of the scheme.

The number of suspect glaucoma cases passing through the scheme averaged out at $23 /$ month. This figure does not represent the total number of new cases seen at MREH, since the hospital receives glaucoma referrals from several different Health Authorities. Expanding the scheme to cover all suspect glaucoma referrals would lead to further savings.

Through the audit route, the study obtains copies of the data collected by the accredited optometrists from patients not referred to the MREH. This information is used in review meetings between the accredited optometrists and the hospital team. We have not independently examined patients not referred to MREH in order to derive an estimate of the false-negative rate. However, the false-negative rate is likely to be low and an analysis is likely to be of limited value. The major problem with regard to detecting cases of glaucoma occurs at the primary examination, ${ }^{10}$ and to assess the extent of this we would have to examine a sample of patients examined by nonaccredited optometrists.

\section{Conclusions}

The optometric referral refinement scheme set up in Manchester has resulted in a $40 \%$ reduction in the number of new glaucoma referrals to the HES. This figure is very close to the number of false referrals identified at MREH in 1997 and to the published false-positive rate. ${ }^{1-7}$ A simple financial analysis has shown an overall cost saving of approximately $£ 17$ / patient passing through the scheme. Patients referred through this scheme are normally examined by the accredited optometrists within 2 weeks of being referred compared to 2-3 months through the old pathway. The data provided by the accredited optometrist can be used as baseline measures for future monitoring of the patient and to prioritise OPD appointments. Our experiences with this new referral pathway have led us to look for ways of extending it to include patients referred from neighbouring health authorities and to consider modifying the referral criteria to allow the optometrists to 'hang onto' certain classes of patients.

\section{Acknowledgement}

This project has been supported by a grant from the Manchester Health Authority.

\section{References}

1 Harrison RJ, Wild JM, Hobley AJ. Referral patterns to an ophthalmic outpatient-clinic by general-practitioners and ophthalmic opticians and the role of these professionals in screening for ocular disease. BMJ 1988; 297: 1162-1167. 
2 Clearkin L, Harcourt B. Referral pattern of true and suspected glaucoma to an adult ophthalmic outpatient clinic. Trans Ophthal Soc UK 1983; 103: 284-287.

3 Theodossiades J, Murdoch L. Positive predictive value of optometrist-initiated referrals for glaucoma. Ophthal Physiol Opt 1999; 19: 62-67.

4 Vernon SA. The changing pattern of glaucoma referrals by optometrists. Eye 1998; 12: 854-857.

5 Bell RWD, OBrien C. The diagnostic outcome of new glaucoma referrals. Ophthal Physiol Opt 1997; 17: 3-6.

6 Bell RWD, OBrien C. Accuracy of referral to a glaucoma clinic. Ophthal Physiol Opt 1997; 17: 7-11.

7 Tuck MW, Crick RP. Efficiency of referral for suspected glaucoma. BMJ 1991; 302: 998-1000.
8 Vernon SA, Ghosh G. Do locally agreed guidelines for optometrists concerning the referral of glaucoma suspects influence referral practice? Eye 2001; 15: 458-463.

9 Bruce Shields M, Tiedeman JS. Binocular ophthalmoscopic techniques for evaluations of the optic nerve head. In: Varma R, Spaeth GL, Parker KW (eds). The Optic Nerve in Glaucoma. JB Lippincott: Philadelphia, 1993, pp 127-136.

10 Tuck MW, Crick RP. Relative effectiveness of differen modes of glaucoma screening in optometric practice. Ophthal Physiol Opt 1993; 13: 227-232.

11 Reidy A, Minassian DC, Vafidis G et al. Prevalence of serious eye disease and visual impairment in a north London population: population based cross sectional study. BMJ 1998; 316: 1643-1646. 